\title{
The Pstl/Rsal and Dral polymorphisms of CYP2E1 and head and neck cancer risk: a meta-analysis based on 21 case-control studies
}

\author{
Kefu Tang ${ }^{1,2}$, Yang Li ${ }^{1,2}$, Zhao Zhang ${ }^{1,2}$, Yunmin Gu', Yuyu Xiong ${ }^{1,2}$, Guoyin Feng ${ }^{4}$, Lin He ${ }^{1,2,3^{*}}$, Shengying Qin ${ }^{1,2^{*}}$
}

\begin{abstract}
Background: CYP2E1 encodes a member of the cytochrome P450 superfamily of enzymes which play a central role in activating and detoxifying many carcinogens and endogenous compounds thought to be involved in the development of cancer. The Pstl/Rsal and Dral polymorphism are two of the most commonly studied polymorphisms of the gene for their association with risk of head and neck cancer, but the results are conflicting.
\end{abstract}

Methods: We performed a meta-analysis using 21 eligible case-control studies with a total of 4,951 patients and 6,071 controls to summarize the data on the association between the CYP2E1 Pst//Rsal and Dral polymorphism and head and neck cancer risk, especially by interacting with smoking or alcohol.

Results: Compared with the wild genotype, the OR was 1.96 (95\% Cl: 1.33-2.90) for Pstl/Rsal and 1.56 (95\% Cl: 1.06-2.27) for Dral polymorphism respectively. When stratified according to ethnicity, the OR increased in the Asians for both polymorphisms ( $\mathrm{OR}=2.04,95 \% \mathrm{Cl}: 1.32-3.15$ for Pstl/Rsal; $\mathrm{OR}=2.04,95 \% \mathrm{Cl}: 1.27-3.29$ for Dral), suggesting that the risk is more pronounced in Asians.

Conclusion: Our meta-analysis suggests that individuals with the homozygote genotypes of Pstl/Rsal or Dral polymorphism might be associated with an increased risk of head and neck cancer, especially in Asians.

\section{Background}

Squamous cell carcinoma of head and neck (HNSCC), including the oral cavity, pharynx, and larynx, is the sixth most common cancer in the world [1]. Epidemiological studies have shown that this type of cancer is one of those most strongly related to environmental factors, such as tobacco smoking and alcohol consumption. Many chemical carcinogens present in tobacco and alcohol undergo metabolic activation by phase I enzymes, in particular the cytochrome P450 (CYP). The activated metabolites are subsequently subjected to other detoxification steps by phase II enzymes such as glutathione S-transferases (GSTs) and N-acetyltransferases (NATs). It is hypothesized that part of the susceptibility to head and neck cancer may be determined by the inter-individual differences in the bioactivation of procarcinogens and

\footnotetext{
* Correspondence: helinhelin@gmail.com; chinsir@sjtu.edu.cn

'Bio-X Center, Key Laboratory for the Genetics of Developmental and Neuropsychiatric Disorders (Ministry of Education), Shanghai Jiao Tong University, Shanghai, China

Full list of author information is available at the end of the article
}

detoxification of carcinogens. CYP2E1, which is a major component of the microsomal system involved in the metabolism of ethanol and acetone among phase I enzymes, has been widely studied as a cause of susceptibility to head and neck cancer $[2,3]$.

The CYP2E1 gene, located on chromosome 10q26.3, is constitutively expressed in human liver and is responsible for the catalysis of xenobiotic. The protein encoded by this gene specifically activates $\mathrm{N}$-nitrosamines and benzene, contained in cigarette smoke [4], and catalyses molecular oxygen to active oxygen forms (e.g., superoxide anion radical, hydrogen peroxide, etc.), which lead to intensified lipid and protein peroxidation, DNA damage, and ultimately carcinogenesis [5]. Several functional polymorphisms have been reported for the CYP2E1 gene. Two point mutations in the 5'-flanking region (PstI, RsaI), which are in complete linkage disequilibrium, was found to be associated with higher-transcription and increased enzyme activity [6]. These mutations generate the CYP2E1 wild (c1) allele and the less common (c2) allele and have been reported as conferring higher risk 
for developing oral, pharyngeal [7] and lung cancer [8]. Another important polymorphism detectable with DraI in intron 6 is T7632A (rs6413432), a mutation of T to A, which is reported to enhance transcription of the $C Y P 2 E 1$ gene [9]. Polymorphisms in CYP2E1 are therefore believed to be risk factors for HNSCC.

A number of studies have investigated the associations between CYP2E1 polymorphisms and HNSCC susceptibility. However, these studies have yielded contradictory results, with some studies showing a significant association, while others showing no such association. Such inconsistency could be due to the small effect of the polymorphism on HNSCC risk and the relatively small sample-size in each of the published studies. We therefore performed a meta-analysis of the published studies to clarify this inconsistency and to establish a comprehensive picture of the relationship between CYP2E1 and HNSCC.

\section{Methods}

\section{Identification and eligibility of relevant studies}

The literature included in the current analysis was selected using PubMed with keywords "head and neck" or "oral-neoplasms" or "larynx" or "pharynx" and "cancer" or "carcinoma", "HNSCC" or "SCCHN", "cytochrome p450 2E1/IIE1", "polymorphism" or "variant" and abbreviations of the gene "Cyp2e1". No other limits were used during electronic search. All references cited in these studies and previously published review articles were reviewed to identify additional work not indexed by MEDLINE. The analyzed data is drawn from all English language publications up to August 2009.

Only those studies assessing the association between head and neck cancer and the CYP2E1 gene polymorphisms were included. Eligible studies had to meet the criteria: (1) They were original papers containing independent data, (2) identification of HNSCC was confirmed histologically or pathologically, (3) they provided sufficient data to calculate the odds ratio (OR) or P-value, (4) they used a case-control design, (5) they described genotyping method, equipment and protocols or made reference to them. The major reasons for exclusion of studies were (1) they were family studies, (2) they contained overlapping data, (3) they were review papers.

\section{Quality assessment and data extraction}

Each article was read and assessed according to the score scale for randomized controlled association study proposed by Dawei et al [10]. In brief, papers were rated according to several items on the scale in relation to two areas: experiment design to minimize potential bias and data analysis. The quality score categorizes studies as of "high" or "low" quality.
For each study, the following information was extracted independently by two investigators: first author's surname, publication date, diagnosis criterion, gender, ethnicity, genotyping method, cigarette smoking status, alcohol consumption, total number of cases and controls and the numbers of cases and controls with the three genotypes. The results were compared and disagreements were discussed and resolved with consensus. Where essential information was not presented in articles, every effort was made to contact the authors.

\section{Statistical analysis}

For the control group of each study, the distributions of genotypes were tested for Hardy-Weinberg equilibrium (HWE) using the Chi-square test. If controls of studies were found not to be in HWE, sensitivity analyses were performed with and without these studies to test the robustness of the findings. For the RsaI/PstI polymorphism, we first estimated the risks of the c1c2 and c2c2 genotypes on HNSCC, compared with the wild-type $\mathrm{c} 1 \mathrm{c} 1$ homozygote. The risk of $\mathrm{c} 1 \mathrm{c} 2+\mathrm{c} 2 \mathrm{c} 2$ versus $\mathrm{c} 1 \mathrm{c} 1$ on cancers was then evaluated in dominant model. The same evaluation was carried out for the DraI polymorphism. The strength of the association between the CYP2E1 polymorphism and head and neck cancer risk was measured by odds ratios (ORs) with $95 \%$ confidence intervals (CIs).

Cochran's $\chi^{2}$ based Q-statistic test $[11,12]$ and $I^{2}$-test [13] were performed to assess possible heterogeneity in the combined studies. If heterogeneity existed, the random effects model (the DerSimonian and Laird method) [14], which yields wider confidence intervals, was adopted to calculate the overall OR value. Otherwise, the fixed effects model (the Mantel-Haenszel method) was used [15]. In addition, sources of heterogeneity were investigated by stratified meta-analyses based on ethnicity (Asian and Caucasian populations), quality (high and low) of the studies, smoking status (ever/ never smokers) and alcohol consumption (users/nonusers). Asian populations are mainly composed of Chinese and Japanese without Indian. 95\% CIs were constructed using Woolf's method [16]. The significance of the overall OR was determined by the Z-test. Funnel plots and Egger's linear regression test were used to assess evidence for potential publication bias [17]. In order to assess the stability of the result, sensitivity analyses were performed, each study in turn was removed from the total, and the remaining were reanalyzed. The analysis was conducted using Comprehensive Meta Analysis software (Version 1.0.23, BIOSTAT, Englewood, $\mathrm{NJ})$. The type I error rate was set at 0.05 . All P-values were two-tailed. 


\section{Results}

\section{Characteristics of studies}

Figure 1 shows the study selection process. The combined search yielded 88 references. After discarding overlapping references and those which clearly did not meet the criteria, 24 studies were retained. One study [18] was discarded for insufficient data (although we tried to contact the authors to query the data), two $[19,20]$ were discarded as being studies on leukoplakia. As shown in table 1, 21 case-control studies finally met our criteria for inclusion [2,3,7,21-38]. 21 studies were identified for the CYP2E1-PstI/RsaI polymorphism, including a total of 4951 cases and 5995 controls, and for the DraI polymorphism 9 studies were identified covering a total of 2510 cases and 2162 controls. The detailed characteristics of these studies are summarized in table 1 .

\section{Meta-analysis results}

\section{CYP2E1-Pstl/Rsal polymorphism}

Our meta-analysis gave an overall OR of 1.96 (95\% CI: 1.33-2.90, $\mathrm{P}<0.001, \mathrm{P}_{\mathrm{Q}}=0.87$ ) for head and neck cancer risk among c2 homozygotes of CYP2E1 RsaI/PstI polymorphism compared with the wild type. However, no other genetic model gave statistically significant results.

When stratifying for ethnicity, $\mathrm{c} 2$ homozygotes were significantly associated with HNSCC in Asian populations with an OR of 2.08(95\% CI: 1.34-3.23, P < 0.001, $\left.\mathrm{P}_{\mathrm{Q}}=0.52\right)$ among homozygotes $(\mathrm{c} 2 \mathrm{c} 2$ versus $\mathrm{c} 1 \mathrm{c} 1)$. On the other hand, no such association was detected in

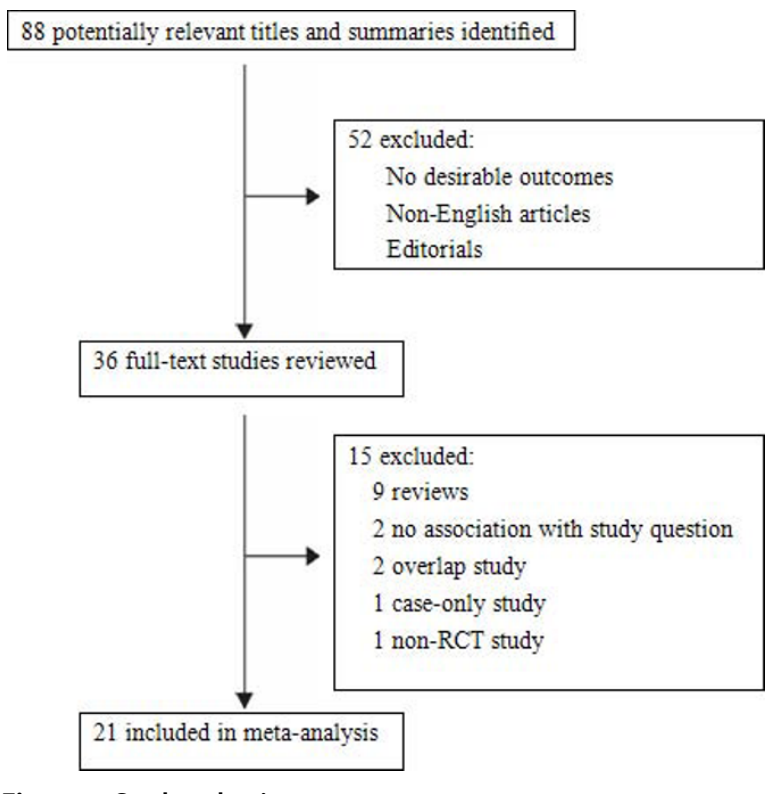

Figure 1 Study selection process.
Caucasian populations ( $\mathrm{p}>0.05$ for all models). When studies were stratified for study quality, an overall OR of 1.81 (95\% CI: $1.13-2.89, \mathrm{P}=0.013, \mathrm{P}_{\mathrm{Q}}=0.92$ ) for $\mathrm{c} 2$ homozygotes emerged for the high-quality scored studies. These positive associations were also present among low-quality scored studies. Data on genotypes of the PstI/RsaI polymorphism among cases and controls stratified by smoking were available in five studies and by alcohol consumption in four studies. The results of the stratified meta-analyses according to smoking status and alcohol consumption are shown in Table 2. The overall ORs appeared similar in each subgroup in all three genetic models.

\section{CYP2E1-Dral polymorphism}

We also carried out a comprehensive meta-analysis of CYP2E1 DraI polymorphisms for each ethnic group and for the different quality grades of studies under various genetic models (Table 3). The overall OR of head and neck cancer was $1.56\left(95 \% \mathrm{CI}: 1.06-2.27, \mathrm{P}=0.021, \mathrm{P}_{\mathrm{Q}}=\right.$ 0.37) for homozygotes compared with wild genotype, but no association was observed between T7632A and head and neck cancer using other genetic models.

After stratification for ethnicity, we observed an OR of 1.99(95\% CI: $1.22-3.24, \mathrm{P}=0.006, \mathrm{P}_{\mathrm{Q}}=0.79$ ) for the DraI polymorphism in Asian populations among homozygotes (AA versus TT), whereas no such association was observed in Caucasian populations. After stratification for study quality, an overall OR of 2.36 (95\% CI: 1.20-4.63, $\mathrm{P}=0.012, \mathrm{P}_{\mathrm{Q}}=0.45$ ) for homozygotes emerged for the low-quality scored studies but no such association was observed among high-quality studies (Table 3).

\section{Sensitivity analyses and Publication bias}

Most studies indicated that the frequency distributions of genotypes in the controls were consistent with Hardy-Weinberg equilibrium (HWE), whereas deviations from HWE were observed in three studies of the PstI/ RsaI polymorphism $[21,28,30]$. However, the corresponding pooled ORs were not substantially altered whether or not these studies were included (Data not shown). In addition, sensitivity analysis indicated that no single study influenced the pooled OR qualitatively, suggesting that the results of this meta-analysis are stable.

Begger's funnel plot and Egger's test were used to assess publication bias. The shape of the funnel plots was symmetrical (Additional file 1). The Egger test provided evidence that there was no publication bias among the studies included ( $\mathrm{p}>0.05$, for all).

\section{Discussion}

In the present meta-analysis, we examined the association between two widely studied CYP2E1 polymorphisms 
Table 1 Demography of the combined studies

\begin{tabular}{|c|c|c|c|c|c|c|c|c|c|c|}
\hline \multirow[t]{3}{*}{ Author, year } & \multirow[t]{3}{*}{ Polymorphism } & \multirow[t]{3}{*}{ Ethnicity } & \multirow[t]{3}{*}{ Cases } & \multirow[t]{3}{*}{ Controls } & \multicolumn{6}{|c|}{ Genotype distribution in controls } \\
\hline & & & & & \multicolumn{3}{|c|}{ Pstl/Rsal } & \multicolumn{3}{|c|}{ Dral } \\
\hline & & & & & $\mathrm{c1c1}$ & $\mathrm{c} 1 \mathrm{c2}$ & $\mathrm{c} 2 \mathrm{c} 2$ & $\mathrm{TT}$ & TA & $A A$ \\
\hline Olivieri et al.,2009 [2] & Pstl/Rsal & Brazilian & 153 & 145 & 105 & 16 & 0 & / & / & I \\
\hline Ruwali et al.,2009 [3] & Pstl/Rsal, Dral & Indian & 350 & 350 & 343 & 7 & 0 & 253 & 94 & 3 \\
\hline Bouchardy et al.,2000 [7] & Pstl/Rsal, Dral & French Caucasians & 250 & 172 & 164 & 8 & 0 & 151 & 20 & 1 \\
\hline Lucas et al.,1996 [21] & Pstl/Rsal, Dral & French Caucasians & 96 & 460 & 248 & 11 & 1 & 368 & 86 & 6 \\
\hline Hildesheim et al.,1997 [22] & Pstl/Rsal, Dral & Taiwanese & 364 & 320 & 198 & 113 & 9 & 183 & 123 & 14 \\
\hline Hung et al.,1997 [23] & Pstl/Rsal & Taiwanese & 41 & 122 & 76 & 42 & 4 & I & I & I \\
\hline González et al.,1998 [24] & Pstl/Rsal & Spaish & 75 & 200 & 179 & 21 & 0 & I & / & I \\
\hline Matthia et al.,1998 [25] & Pstl/Rsal, Dral & German Caucasians & 398 & 219 & 165 & 10 & 0 & 102 & 17 & 2 \\
\hline Morita et al.,1999 [26] & Pstl/Rsal & Japanese & 145 & 164 & 105 & 52 & 7 & / & I & / \\
\hline Katoh et al.,1999 [27] & Pstl/Rsal & Japanese & 92 & 146 & 95 & 45 & 7 & I & I & 1 \\
\hline Kongruttanachok et al.,2001 [28] & Pstl/Rsal & Thai & 217 & 297 & 189 & 103 & 5 & / & / & / \\
\hline Liu et al., 2001 [29] & Pstl/Rsal & American & 174 & 399 & 384 & 15 & 0 & I & I & I \\
\hline Neuhaus et al.,2004 [30] & Pstl/Rsal, Dral & German & 312 & 299 & 282 & 13 & 2 & 196 & 39 & 1 \\
\hline Li et al.,2005 [31] & Pstl/Rsal & White American & 724 & 1226 & 1137 & 86 & 3 & I & I & 1 \\
\hline Gajecka et al.,2005 [32] & Pstl/Rsal & Poland Caucasians & 289 & 316 & 305 & 18 & 0 & / & / & / \\
\hline Sugimura et al.,2006 [33] & Pstl/Rsal, Dral & Japanese & 122 & 241 & 164 & 70 & 7 & 126 & 97 & 18 \\
\hline Gattáet al.,2006 [34] & Pstl/Rsal & Brazilian & 103 & 102 & 96 & 6 & 0 & I & I & 1 \\
\hline Marques et al.,2006 [35] & Pstl/Rsal & Brazilian & 231 & 212 & 187 & 25 & 0 & I & I & I \\
\hline Soya et al.,2008 [36] & Pstl/Rsal, Dral & Indian & 408 & 220 & 212 & 8 & 0 & 145 & 65 & 10 \\
\hline Shama et al., 2008 [37] & Pstl/Rsal & White American & 197 & 416 & 364 & 39 & 0 & I & I & / \\
\hline Boccia et al.,2008 [38] & Pstl/Rsal, Dral & Italian & 210 & 245 & 228 & 15 & 1 & 224 & 19 & 1 \\
\hline
\end{tabular}

(PstI/RsaI, DraI) and head and neck cancer risk. We found that the variant homozygote of the CYP2E1 PstI/ Rsal polymorphism was significantly associated with cancer risk in the overall comparisons, compared with the wild homozygote. We also observed a significant association between the CYP2E1 DraI polymorphism and cancer risk for homozygote in the overall comparisons.

As for the PstI/RsaI polymorphism of CYP2E1, our result showed a significantly high cancer risk for the $\mathrm{c} 2$ homozygote in Asian populations, with no such association being found among Caucasian population under any of the three genetic models. Ethnic differences may attribute to these different results, since the distributions of the less common c2 allele were different between various races, with a prevalence of $\sim 25-50 \%$ and $5-10 \%$ among Asians and Caucasians, respectively [39]. The c2 variant allele frequency did reach a statistically significant level among Asians, while in the Caucasian populations, the lack of significant association might be explained by the substantially lower statistical power caused by the lower prevalence of $C Y P 2 E 1 \mathrm{c} 2$ allele (5-10\% against $25-50 \%$ for Asians).

CYP2E1 is presumed to confer susceptibility to HNSCC by metabolizing carcinogens but, unfortunately, few of the studies explored the interaction between the
CYP2E1 genotype and smoking habits or alcohol consumption. This may be due to the low statistical power of the individual studies to detect such interactions; but all the studies which collected these data were utilized for this meta-analysis. The stratified meta-analyses of all the data on the PstI/RsaI genotype and smoking habits or alcohol consumption with respect to head and neck cancer risk produced no statistically significant results. These results suggest that when the environmental and genetic risk factors are both present, the combined effect on head and neck cancer seems to be no longer than additive of the separate effects. However, we cannot ignore the fact that owing to the low prevalence of c2 homozygotes in each study, even when data are pooled, the statistical power to detect an interaction remains low.

In addition, the DraI polymorphism was associated with an increased cancer risk among Asians but not among Caucasians, suggesting an ethnic difference in terms of genetic and environmental factors [40]. However, only two studies of the DraI polymorphisms used Asian population data and it is therefore probable that the observed ethnic differences were simply due to chance, given that studies with small sample size may have insufficient statistical power to detect a slight 
Table 2 Stratified analysis of the CYP2E1 Rsal/Pstl polymorphism and HNSCC

\begin{tabular}{|c|c|c|c|c|c|c|c|c|}
\hline \multirow[t]{2}{*}{ Sub-grouped studies } & \multirow[t]{2}{*}{ Genetic model } & \multirow[t]{2}{*}{ No.of Studies } & \multirow[t]{2}{*}{ No.Cases/No.Controls } & \multicolumn{2}{|c|}{ Test of association } & \multicolumn{3}{|c|}{ Test of heterogeneity } \\
\hline & & & & OR $(95 \% \mathrm{Cl})$ & $\mathbf{P}$ & $Q$ & $\mathrm{P}_{\mathrm{Q}}$ & $I^{2}$ \\
\hline \multirow[t]{3}{*}{ Overall } & C2 carriers vs. wild & 21 & $4892 / 5995$ & $1.02(0.90-1.17)$ & 0.68 & 31.37 & 0.05 & 36.26 \\
\hline & c2 homozygotes vs. wild & 17 & $3920 / 5008$ & $1.96(1.33-2.90)$ & $<0.001$ & 9.84 & 0.87 & 0 \\
\hline & Dominant & 21 & $4892 / 5995$ & $1.08(0.95-1.22)$ & 0.23 & 30.68 & 0.06 & 34.81 \\
\hline \multirow[t]{3}{*}{ Asians } & C2 carriers vs. wild & 6 & $981 / 1291$ & $1.03(0.86-1.24)$ & 0.69 & 5.95 & 0.31 & 16.01 \\
\hline & c2 homozygotes vs. wild & 6 & $981 / 1291$ & $2.08(1.34-3.23)$ & $<0.001$ & 4.17 & 0.52 & 0 \\
\hline & Dominant & 6 & $981 / 1291$ & $1.12(0.94-1.33)$ & 0.18 & 4.76 & 0.44 & 0 \\
\hline \multirow[t]{3}{*}{ Caucasians } & C2 carriers vs. wild & 15 & $3911 / 4704$ & $1.07(0.82-1.40)$ & 0.57 & 25.40 & 0.03 & 44.89 \\
\hline & c2 homozygotes vs. wild & 11 & 2939/3717 & $1.58(0.68-3.68)$ & 0.28 & 5.35 & 0.86 & 0 \\
\hline & Dominant & 15 & $3911 / 4704$ & $1.03(0.86-1.24)$ & 0.49 & 25.49 & 0.03 & 45.09 \\
\hline \multirow[t]{3}{*}{ High quality } & c2 carriers vs. wild & 16 & $3914 / 4688$ & $1.08(0.86-1.35)$ & 0.48 & 26.49 & 0.033 & 43.38 \\
\hline & c2 homozygotes vs. wild & 13 & $3173 / 3913$ & $1.81(1.13-2.89)$ & 0.013 & 5.76 & 0.92 & 0 \\
\hline & Dominant & 16 & $3914 / 4688$ & $1.11(0.90-1.37)$ & 0.29 & 24.09 & 0.064 & 37.74 \\
\hline \multirow[t]{3}{*}{ Low quality } & c2 carriers vs. wild & 5 & 978/1307 & $1.07(0.84-1.36)$ & 0.57 & 4.71 & 0.31 & 15.11 \\
\hline & c2 homozygotes vs. wild & 4 & $747 / 1095$ & $2.36(1.16-4.79)$ & 0.017 & 3.70 & 0.29 & 19.04 \\
\hline & Dominant & 5 & 978/1307 & $1.12(0.81-1.55)$ & 0.46 & 6.38 & 0.17 & 37.39 \\
\hline \multirow[t]{3}{*}{ Ever-smokers } & c2 carriers vs. wild & 5 & 1173/831 & $0.62(0.34-1.12)$ & 0.11 & 8.67 & 0.07 & 53.88 \\
\hline & c2 homozygotes vs. wild & 2 & $385 / 325$ & $0.47(0.15-1.47)$ & 0.19 & 0.10 & 0.74 & 0 \\
\hline & Dominant & 5 & 1173/831 & $0.61(0.33-1.11)$ & 0.10 & 8.93 & 0.063 & 55.19 \\
\hline \multirow[t]{3}{*}{ Never-smokers } & c2 carriers vs. wild & 4 & $549 / 677$ & $1.40(0.93-2.11)$ & 0.09 & 0.44 & 0.93 & 0 \\
\hline & c2 homozygotes vs. wild & 3 & $441 / 431$ & $3.25(0.48-21.70)$ & 0.22 & 3.66 & 0.16 & 45.43 \\
\hline & Dominant & 4 & $549 / 677$ & $1.45(0.98-2.16)$ & 0.06 & 1.19 & 0.75 & 0 \\
\hline \multirow[t]{3}{*}{ Alcohol- drinkers } & C2 carriers vs. wild & 4 & $565 / 467$ & $1.12(0.51-2.43)$ & 0.76 & 8.39 & 0.039 & 64.26 \\
\hline & c2 homozygotes vs. wild & 2 & 198/296 & $1.48(0.34-6.44)$ & 0.59 & 0.83 & 0.36 & 0 \\
\hline & Dominant & 4 & $565 / 467$ & $1.11(0.53-2.29)$ & 0.77 & 7.58 & 0.055 & 60.43 \\
\hline \multirow[t]{3}{*}{ Non-drinkers } & C2 carriers vs. wild & 3 & $653 / 883$ & $0.92(0.64-1.33)$ & 0.69 & 1.31 & 0.51 & 0 \\
\hline & c2 homozygotes vs. wild & 2 & $443 / 370$ & $2.22(0.93-5.30)$ & 0.07 & 0.004 & 0.94 & 0 \\
\hline & Dominant & 3 & $653 / 883$ & $1.07(0.76-1.52)$ & 0.67 & 1.08 & 0.58 & 0 \\
\hline
\end{tabular}

Table 3 Stratified analysis of the CYP2E1 Dral polymorphism and HNSCC

\begin{tabular}{|c|c|c|c|c|c|c|c|c|}
\hline \multirow[t]{2}{*}{ Sub-grouped studies } & \multirow[t]{2}{*}{ Genetic model } & \multirow[t]{2}{*}{ No.of Studies } & \multirow[t]{2}{*}{ No.Cases/No.Controls } & \multicolumn{2}{|c|}{ Test of association } & \multicolumn{3}{|c|}{ Test of heterogeneity } \\
\hline & & & & OR $(95 \% \mathrm{Cl})$ & $P$ & Q & $\mathrm{P}_{\mathrm{Q}}$ & $I^{2}$ \\
\hline \multirow[t]{3}{*}{ Overall } & AT vs. TT & 9 & $2407 / 2126$ & $1.15(0.90-1.47)$ & 0.25 & 19.92 & 0.011 & 59.84 \\
\hline & AA vs. TT & 9 & $2407 / 2126$ & $1.56(1.06-2.27)$ & 0.021 & 8.62 & 0.37 & 7.21 \\
\hline & Dominant & 9 & $2407 / 2126$ & $1.18(0.94-1.49)$ & 0.13 & 18.81 & 0.016 & 57.47 \\
\hline \multirow[t]{3}{*}{ Asians } & AT vs. TT & 2 & $486 / 561$ & $0.92(0.70-1.19)$ & 0.53 & 0.13 & 0.71 & 0 \\
\hline & AA vs. TT & 2 & $486 / 561$ & $1.99(1.22-3.24)$ & 0.006 & 0.067 & 0.79 & 0 \\
\hline & Dominant & 2 & $486 / 561$ & $1.04(0.81-1.34)$ & 0.72 & 0.37 & 0.53 & 0 \\
\hline \multirow[t]{3}{*}{ Caucasians } & AT vs. $\Pi$ & 7 & $1921 / 1601$ & $1.24(0.92-1.66)$ & 0.15 & 14.61 & 0.02 & 58.95 \\
\hline & AA vs. TT & 7 & $1921 / 1601$ & $1.08(0.59-1.97)$ & 0.78 & 6.18 & 0.40 & 2.98 \\
\hline & Dominant & 7 & $1921 / 1601$ & $1.22(0.90-1.65)$ & 0.18 & 16.29 & 0.01 & 63.17 \\
\hline \multirow[t]{3}{*}{ High quality } & AT vs. TT & 7 & $2189 / 1663$ & $1.12(0.83-1.51)$ & 0.43 & 18.33 & 0.005 & 67.27 \\
\hline & $\overline{A A}$ vs. TT & 7 & $2189 / 1663$ & $1.28(0.81-2.03)$ & 0.28 & 5.89 & 0.43 & 0 \\
\hline & Dominant & 7 & $2189 / 1663$ & $1.13(0.85-1.49)$ & 0.38 & 17.11 & 0.009 & 64.93 \\
\hline \multirow[t]{3}{*}{ Low quality } & AT vs. TT & 2 & 218/499 & $1.19(0.82-1.72)$ & 0.35 & 1.59 & 0.20 & 37.10 \\
\hline & $\overline{A A}$ vs. TT & 2 & $218 / 499$ & $2.36(1.20-4.63)$ & 0.012 & 0.56 & 0.45 & 0 \\
\hline & Dominant & 2 & $218 / 499$ & $1.35(0.95-1.92)$ & 0.085 & 1.25 & 0.26 & 20.00 \\
\hline
\end{tabular}


effect. Additional studies are therefore required to further validate ethnic differences in the effect of DraI polymorphisms on cancer risk, especially in Asian populations.

Currently, the mechanism whereby the rare allele of the Rsal/PstI and DraI polymorphisms increases the risk of head and neck cancer risk are still not clear. CYP2E1 is a phase I enzyme, which plays an essential role in the metabolic activation of low molecular weight compounds and pro-carcinogens such as $\mathrm{N}$-nitrosamines, benzene, and halogenated hydrocarbons. There is strong evidence from in vitro studies suggesting that the rare allele of the RsaI/PstI polymorphisms in the CYP2E1 gene probably confers a higher risk of HNSCC susceptibility by increasing transcriptional and enzyme activity [6]. Thus, the $c 2 / c 2$ genotypes may be more liable to metabolically activate mutagens and carcinogens. As for the rare allele of the DraI polymorphism of the CYP2E1 gene, in vitro expression studies indicate that it is associated with increased transcriptional activity [9]. The AA genotypes may therefore have more ability to metabolize mutagens and pro-carcinogens.

Some limitations should be considered when interpreting our results, in addition to those inherited from the meta-analysis. First, our results are based on unadjusted estimates, whereas adjustments for factors such as age and sex would produce a more precise analysis. The lack of this kind of information may cause serious confounding bias. Further large and well-designed studies need to be performed to further confirm all these results. Secondly, the subgroup meta-analyses dealing with interactions between the CYP2E1 genotype and smoking habits/alcohol consumption are based on the small number of studies where such information is available. Nevertheless the number of subjects included in this part of the analysis comprised the largest sample of all. Third, the quality score of the individual studies included in our meta-analysis was assessed on the basis of trying to minimize the potential for selection bias, misclassification related to exposure, collection of data on potential confounders and method of statistical analysis. No validated quality assessment system currently exists, and it is evident that our quality scale has a subjective component.

\section{Conclusions}

In summary, this may be the first systematic and comprehensive meta-analysis of CYP2E1 and HNSCC. Our results indicate that the CYP2E1-PstI/RsaI and DraI polymorphisms may be a risk factor for head and neck cancer in Asian populations, and particularly for individual homozygotes for the unfavourable gene variant. However additional large studies are needed to validate our findings. Future studies should use standardized unbiased genotyping methods as well as homogeneous cancer patients and well-matched controls.

\section{Additional material}

Additional file 1: T-test and Funnel plot. Egger's test and Begger's

funnel plot results to assess publication bias.

\section{Abbreviations}

HNSCC: squamous cell carcinoma of head and neck; OR: odds ratio; Cl: confidence interval; HWE: Hardy-Weinberg equilibrium.

\section{Acknowledgements}

We thank Dr Devendra Parmar, Dr Soya Sisy Sam, Dr Qingyi Wei, Dr Silvia Regina Rogatto, Dr Stefania Boccia and Dr Marjorie Romkes for their collaboration and for making their data available for the present metaanalysis. This work was supported by grants (2007CB947300, 07DZ22917, 2010CB529600, and 09DJ1400601, 2006AA02A407), National Natural Science Foundation of China (30900799), the Shanghai Natural Science Foundation, No 07ZR14058, the National Key Project for Investigational New Drug (2008ZX09312-003), the Shanghai Changning Health Bureau program (2008406002), the Shanghai Municipal Health Bureau program (2008095), the Shanghai Municipal Commission of Science and Technology Program (09DJ1400601) and the Shanghai Leading Academic Discipline Project (B205).

\section{Author details}

'Bio-X Center, Key Laboratory for the Genetics of Developmental and Neuropsychiatric Disorders (Ministry of Education), Shanghai Jiao Tong University, Shanghai, China. ${ }^{2}$ Institute for Nutritional Sciences, Shanghai Institutes of Biological Sciences, Chinese Academy of Sciences, Shanghai, China. ${ }^{3}$ Institutes of Biomedical Sciences, Fudan University, Shanghai, China. ${ }^{4}$ Shanghai Institute of Mental Health, Shanghai, China.

\section{Authors' contributions}

KFT organized all the research, performed data analysis and drafted the manuscript. YL collected the articles, co-worked in data analysis, as well as manuscript preparation. ZZ participated in the calculation and table generation, and helped to draft the manuscript. YMG and YYX participated in the data extraction and manuscript editing. GYF, LH and SYQ provided advice for preparing the manuscript. All authors read and approved the final manuscript.

\section{Competing interests}

The authors declare that they have no competing interests.

Received: 20 October 2009 Accepted: 22 October 2010 Published: 22 October 2010

\section{References}

1. Hunter KD, Parkinson EK, Harrison PR: Profiling early head and neck cancer. Nat Rev Cancer 2005, 5:127-135.

2. Olivieri EH, da Silva SD, Mendonça FF, Urata YN, Vidal DO, Faria MD, Nishimoto IN, Rainho CA, Kowalski LP, Rogatto SR: CYP1A2*1C, CYP2E1*5B, and GSTM1 polymorphisms are predictors of risk and poor outcome in head and neck squamous cell carcinoma patients. Oral Oncol 2009, 45: e73-e79.

3. Ruwali M, Khan AJ, Shah PP, Singh AP, Pant MC, Parmar D: Cytochrome P450 2E1and Head and Neck Cancer: Interaction with Genetic and Environmental Risk Factors. Environmental and Molecular Mutagenesis 2009 50:473-482.

4. Guengerich FP, Kim DH, Iwasaki M: Role of human cytochrome P-450 IIE1 in the oxidation of many low molecular weight cancer suspects. Chem Res Toxicol 1991, 4:168-179.

5. Ingelman-Sundberg $M$, Johansson I, Yin H, Terelius $Y$, Eliasson $E$, Clot $P$, Albano E: Ethanol-inducible cytochrome P4502E1: Genetic 
polymorphism, regulation, and possible role in the etiology of alcoholinduced liver disease. Alcohol 1993, 10:447-452.

6. Hayashi S, Watanabe J, Kawajiri K: Genetic polymorphisms in the 5'flanking region change transcriptional regulation of the human cytochrome P450IIE1 gene. J. Biochem 1991, 110:559-565.

7. Bouchardy C, Hirvonen A, Coutelle C, Ward PJ, Dayer P, Benhamou S: Role of alcohol dehydrogenase 3 and cytochrome P-4502E1 genotypes in susceptibility to cancers of the upper aerodigestive tract. Int $J$ Cancer 2000, 87:734-740.

8. Le Marchand L, Sivaraman L, Pierce L, Seifried A, Lum A, Wilkens LR, Lau AF: Associations of CYP1A1, GSTM1, and CYP2E1 polymorphisms with lung cancer suggest cell type specificities to tobacco carcinogens. Cancer Res 1998, 58:4858-4863.

9. Uematsu F, Ikawa S, Kikuchi S, Sagami I, Kanamaru R, Abe T, Satoh K, Motomiya M, Watanabe M: Restriction fragment length polymorphism of the human CYP2E1 (cytochrome P450IIE1) gene and susceptibility to lung cancer: Possible relevance to low smoking exposure. Pharmacogenetics 1994, 4:58-63.

10. Li D, L He: Further clarification of the contribution of the tryptophan hydroxylase (TPH) gene to suicidal behavior using systematic allelic and genotypic meta-analyses. Hum Genet 2006, 119:233-240.

11. Cochran WG: The combination of estimates from different experiments. Biometrics 1954, 10:101-129.

12. Colditz GA, Burdick E, Mosteller F: Heterogeneity in meta-analysis of data from epidemiologic studies: A commentary. Am J Epidemiol 1995, 142(4):371-382.

13. Higgins JP, Thompson SG, Deeks JJ, Altman DG: Measuring inconsistency in meta-analyses. BMJ 2003, 327:557-560.

14. DerSimonian R, Laird N: Meta-analysis in clinical trials. Control Clin Trials 1986, 7:177-188.

15. Mantel $\mathrm{N}$, Haenszel W: Statistical aspects of the analysis of data from retrospective studies of disease. J Natl Cancer Inst 1959, 22:719-748.

16. Woolf $\mathrm{B}$ : On estimating the relation between blood group and disease. Ann Hum Genet 1955, 19:251-253.

17. Egger M, Davey Smith G, Schneider M, Minder C: Bias in meta-analysis detected by a simple, graphical test. BMJ 1997, 315:629-634.

18. Jahnke V, Strange R, Matthias C, Fryer A: Glutathione S-transferase and cytochrome P450 genotypes as risk factors for laryngeal carcinoma. Eur Arch Otorhinolaryngol 1997, 254(suppl. 1):S147-S149.

19. Duarte EC, Ribeiro DC, Gomez MV, Ramos-Jorge ML, Gomez RS: Genetic Polymorphisms of Carcinogen Metabolizing Enzymes are Associated with Oral Leukoplakia Development and p53 Overexpression. Anticancer Research 2008, 28:1101-1106.

20. Sikdar N, Mahmud SA, Paul RR, Roy B: Polymorphism in CYP1A1 and CYP2E1 genes and susceptibility to leukoplakia in Indian tobacco users. Cancer Letters 2003, 195:33-42.

21. Lucas D, Menez C, Floch F, Gourlaouen Y, Sparfel O, Joannet I: Cytochromes P4502E1 and P4501A1 genotypes and susceptibility to cirrhosis or upper aerodigestive tract cancer in alcoholic Caucasians. Alcohol Clin Exp Res 1996, 20:1033-1037.

22. Hildesheim A, Anderson LM, Chen CJ: CYP2E1 genetic polymorphisms and risk of nasopharyngeal carcinoma in Taiwan. J Natl Cancer Inst 1997, 89:1207-1212.

23. Hung HC, Chuang J, Chien YC, Chern HD, Chiang CP, Kuo YS: Genetic polymorphisms of CYP2E1, GSTM1, and GSTM3; environmental factors and risk of oral cancer. Cancer Epidemiol Biomarkers Prev 1997, 6:901-905.

24. González MV, Alvarez V, Pello MF, Menéndez MJ, Suárez C, Coto E: Genetic polymorphism of $\mathrm{N}$-acetyltransferase-2, glutathione S-transferase-M1, and cytochromes P450IIE1 and P450IID6 in the susceptibility to head and neck cancer. Journal of Clinical Pathology 1998, 51(4):294-298.

25. Matthias C, Bockmühl U, Jahnke V, Jones PW, Hayes JD, Alldersea J, Gilford J, Bailey L, Bath J, Worrall SF, Hand P, Fryer AA, Strange RC: Polymorphism in cytochrome P450 CYP2D6, CYP1A1, CYP2E1 and glutathione S-transferase, GSTM1, GSTM3, GSTT1 and susceptibility to tobacco-related cancers: studies in upper aerodigestive tract cancers. Pharmacogenetics 1998, 8(2):91-100.

26. Morita S, Yano M, Tsujinaka T, Akiyama Y, Taniguchi M, Kaneko K, Miki $\mathrm{H}_{\text {, }}$ Fujii T, Yoshino K, Kusuoka H, Monden M: Genetic Polymorphisms of Drug-Metabolizing Enzymes and Susceptibility to Head-and-Neck Squamous-Cell Carcinoma. Int I Cancer 1999, 80:685-688.
27. Katoh T, Kaneko S, Kohshi K, Munaka M, Kitagawa K, Kunugita N, Ikemura K, Kawamoto T: Genetic polymorphisms of tobacco- and alcohol-related metabolizing enzymes and oral cavity cancer. Int J Cancer 1999, 83:606-609.

28. Kongruttanachok N, Sukdikul S, Setavarin S: Cytochrome P450 2E1 polymorphism and nasopharyngeal carcinoma development in Thailand: a correlative study. BMC Cancer 2001, 1:4.

29. Liu S, Park JY, Schantz SP, Stern JC, Lazarus P: Elucidation of CYP2E1 5' regulatory Rsal/Pstl allelic variants and their role in risk for oral cancer. Oral Oncol 2001, 37:437-445.

30. Neuhaus T, Ko YD, Lorenzen K, Fronhoffs S, Harth V, Bröde P, Vetter $H$, Bolt HM, Pesch B, Brüning T: Association of cytochrome P450 2E1 Polymorphisms and head and neck squamous cell cancer. Toxicol Lett 2004, 151:273-282

31. Li G, Liu Z, Sturgis EM, Chamberlain RM, Spitz MR, Wei Q: CYP2E1 G1532C, NQO1 Pro187Ser, and CYP1B1 Val432Leu polymorphisms are not associated with risk of squamous cell carcinoma of the head and neck. Cancer Epidemiol Biomarkers Prev 2005, 14:1034-1036.

32. Gajecka M, Rydzanicz M, Jaskula-Sztul R, Kujawski M, Szyfter W, Szyfter K: CYP1A1, CYP2D6, CYP2E1, NAT2, GSTM1 and GSTT1 polymorphisms or their combinations are associated with the increased risk of the laryngeal squamous cell carcinoma. Mutat Res 2005, 574:112-123.

33. Sugimura T, Kumimoto H, Tohnai I, Fukui T, Matsuo K, Tsurusako S: Geneenvironment interaction involved in oral carcinogenesis: molecular epidemiological study for metabolic and DNA repair gene polymorphisms. J Oral Pathol Med 2006, 35:11-18.

34. Gattá GJF, de Carvalho MB, Siraque MS: Genetic polymorphisms of CYP1A1, CYP2E1, GSTM1, and GST1 associated with head and neck cancer. Head \& Neck 2006, 28(9):819-826.

35. Marques CFS, Koifman S, Koifman RJ, Boffetta P, Brennan P, Hatagima A: Influence of CYP1A1, CYP2E1, GSTM3 and NAT2 genetic polymorphisms in oral cancer susceptibility: results from a case-control study in Rio de Janeiro. Oral Oncology 2006, 42(6):632-637.

36. Soya SS, Vinod T, Reddy KS, Gopalakrishnan S, Adithan C: CYP2E1 polymorphisms and gene-environment interactions in the risk of upper aerodigestive tract cancers among Indians. Pharmacogenomics 2008 , 9:551-560

37. Buch Shama C, Nazar-Stewart Valle, Joel L, Weissfeld MarjorieRomkes: Casecontrol study of oral and oropharyngeal cancer in whites and genetic variation in eight metabolic enzymes. Head \& neck 2008, 30:1139-1147.

38. Boccia S, Cadoni G, Sayed-Tabatabaei FA, Volante M, Arzani D, De Lauretis A, Cattel C, Almadori G, van Duijn CM, Paludetti G, Ricciardi G: CYP1A1, CYP2E1, GSTM1, GSTT1, EPHX1 exons 3 and 4, and NAT2 polymorphisms, smoking, consumption of alcohol and fruit and vegetables and risk of head and neck cancer. J Cancer Res Clin Oncol 2008, 134:93-100.

39. Garte S, Gaspari L, Alexandrie AK: Metabolic gene polymorphism frequencies in control populations. Cancer Epidemiol Biomarkers Prev 2001, 10:1239-1248.

40. Hirschhorn JN, Lohmueller K, Byrne E, Hirschhorn K: A comprehensive review of genetic association studies. Genet 2002, 4:45-61.

Pre-publication history

The pre-publication history for this paper can be accessed here: http://www.biomedcentral.com/1471-2407/10/575/prepub

doi:10.1186/1471-2407-10-575

Cite this article as: Tang et al:: The Pstl/Rsal and Dral polymorphisms of CYP2E1 and head and neck cancer risk: a meta-analysis based on 21 case-control studies. BMC Cancer 2010 10:575. 